\title{
Nitrogen Doped Carbon Nanotubes and Nanofibers for Green Hydrogen Production: Similarities in the Nature of Nitrogen Species, Metal-Nitrogen Interaction, and Catalytic Properties
}

\author{
Olga Podyacheva ${ }^{1,2}, * \mathbb{0}$, Alexander Lisitsyn ${ }^{1}$, Lidiya Kibis ${ }^{1,2}$, Andrei Boronin ${ }^{1,2} \odot$, \\ Olga Stonkus 1,2, Vladimir Zaikovskii 1,2, Arina Suboch ${ }^{1}$, Vladimir Sobolev ${ }^{1}$ \\ and Valentin Parmon 1,2 \\ 1 Boreskov Institute of Catalysis, SB RAS, Novosibirsk 630090, Russia; liss@catalysis.ru (A.L.); \\ kibis@catalysis.ru (L.K.); boronin@catalysis.ru (A.B.); stonkus@catalysis.ru (O.S.); viz@catalysis.ru (V.Z.); \\ arina@catalysis.ru (A.S.); visobo@catalysis.ru (V.S.); parmon@catalysis.ru (V.P.) \\ 2 Novosibirsk State University, Novosibirsk 630090, Russia \\ * Correspondence: pod@catalysis.ru
}

Received: 20 September 2019; Accepted: 17 October 2019; Published: 18 October 2019

check for updates

\begin{abstract}
The effect of nitrogen doped bamboo-like carbon nanotubes (N-CNTs) on the properties of supported platinum ( 0.2 and $1 \mathrm{wt} \%$ ) catalysts in formic acid decomposition for hydrogen production was studied. It was shown that both impregnation and homogeneous precipitation routes led to the formation of electron-deficient platinum stabilized by pyridinic nitrogen sites of the N-CNTs. The electron-deficient platinum species strongly enhanced the activity and selectivity of the Pt/N-CNTs catalysts when compared to the catalysts containing mainly metallic platinum nanoparticles. A comparison of bamboo-like N-CNTs and herring-bone nitrogen doped carbon nanofibers ( $\mathrm{N}-\mathrm{CNFs}$ ) as the catalyst support allowed us to conclude that the catalytic properties of supported platinum are determined by its locally one-type interaction with pyridinic nitrogen sites of the N-CNTs or N-CNFs irrespective of substantial structural differences between nanotubes and nanofibers.
\end{abstract}

Keywords: hydrogen; formic acid; platinum; nitrogen doped; carbon nanotubes; carbon nanofibers

\section{Introduction}

Hydrogen is considered as a promising energy source although its safe storage and transportation are rather complicated tasks. In this connection, the concept of hydrogen storage as a component of various hydrogen-rich compounds such as borohydrates, hydrazine, or formic acid has recently received considerable attention. Among such compounds, formic acid (FA) is of particular interest. First, $\mathrm{HCOOH}$ contains a large amount of hydrogen $(4.4 \mathrm{wt} \%)$, and second, FA can be synthesized from renewable sources, for example, via different transformations of cellulose, which certainly makes $\mathrm{HCOOH}$ an attractive source of hydrogen [1].

It is known that the decomposition of FA on homogeneous or heterogeneous metal catalysts can proceed via two routes, leading to the formation of either $\mathrm{H}_{2}$ and $\mathrm{CO}_{2}$ or $\mathrm{H}_{2} \mathrm{O}$ and $\mathrm{CO}$. Thus, in the case of heterogeneous catalysts, the reaction rate and selectivity of hydrogen formation depend on the sizes, morphologies, distributions, and surface states of metal nanoparticles as well as the properties of catalyst support $\left(\mathrm{CeO}_{2}, \mathrm{SiO}_{2}, \mathrm{C}, \mathrm{C}-\mathrm{N}\right.$, etc.) [2]. Among the various types of supports for metal catalysts used for FA decomposition, carbon materials are of special interest because they allow the size and electronic state of supported metal nanoparticles to be controlled more precisely [3,4]. Moreover, 
the application of nitrogen doped carbon nanomaterials (N-CNMs) or carbon nitride makes it possible to obtain stable single atom species exhibiting high activity and selectivity in the FA decomposition reaction $[5,6]$. Stabilization of these highly active species proceeds via strong interaction of metal with pyridinic nitrogen centers of nitrogen doped carbon nanofibers ( $\mathrm{N}-\mathrm{CNFs})$, nitrogen doped carbon nanotubes (N-CNTs), or $\mathrm{C}_{3} \mathrm{~N}_{4}$, which has been confirmed by $x$-ray photoelectron spectroscopy (XPS) data and density functional theory (DFT) calculations [5,7-11].

According to the literature, the synthesis method substantially affects the particle size and electronic state of metals deposited on N-CNMs. For example, for the Pd catalyst supported on $\mathrm{N}-\mathrm{CNFs}$ and nitrogen-doped porous carbon network, we demonstrated that Pd acetate is more preferable than $\mathrm{Pd}$ nitrate for the synthesis of a more dispersed, and therefore more active catalyst [7]. Moreover, when palladium was deposited from Pd acetate on N-CNTs in the amount of $<0.8 \mathrm{wt} \%$, $100 \%$ of palladium was represented by highly active isolated ions showing stability in both a hydrogen atmosphere at elevated temperatures and in the course of the $\mathrm{HCOOH}$ decomposition reaction [12]. The authors of [8] investigated the properties of $0.5-5 \% \mathrm{Pt} / \mathrm{N}-\mathrm{CNTs}$ catalysts synthesized with $\mathrm{H}_{2} \mathrm{PtCl}_{6}$ as a precursor using different deposition methods: ethylene glycol reduction, sodium borohydride reduction, or impregnation- $\mathrm{H}_{2}$-reduction techniques. It was found that the difference between synthesis routes was caused by the different metal-support interaction (MSI) between the Pt and nitrogen species, and the impregnation technique led to the strongest MSI via defects in N-CNTs comprising carbon vacancies and pyridinic nitrogen. As a result, a correlation between the binding energies of $\mathrm{Pt}_{4 \mathrm{f}} \mathrm{f/2}$ $\left(\mathrm{E}_{\mathrm{b}} \mathrm{Pt}_{4} \mathrm{f}_{7 / 2}\right)$ and activity in the electro-oxidation of glycerol and formic acid was found. Previously, we have shown that such types of defect can form in the graphene layer of N-CNTs [13].

Our earlier comparative study of Pt-group metals (Pt, Pd, $\mathrm{Ru}$ ) deposited on herring-bone N-CNFs revealed that the activity of the catalysts toward formic acid decomposition decreases in the following order: $\mathrm{Pt}>\mathrm{Pd}>\mathrm{Ru}$ [5]. DFT calculations made it possible to propose the active site consisting of a metal atom coordinated by a pair of pyridinic nitrogen atoms at the edges of the graphene sheets. Indeed, it is known that multiple edges of graphene layers enriched with pyridinic nitrogen are segregated to the surface of $\mathrm{N}-\mathrm{CNFs}$ [14], which explains the preferential interaction of deposited metals with these sites. In this connection, it seems interesting to explore the interaction of metals with $\mathrm{N}-\mathrm{CNMs}$ with another structure, for example, with the widely used bamboo-like N-CNTs where all nitrogen species (pyridinic, pyrrolic, and graphitic) are located within internal and external graphene layers [15] and can equiprobably participate in the stabilization of deposited metals.

This paper is devoted to the investigation of the effect of the bamboo-like N-CNTs on the properties of $\mathrm{Pt} / \mathrm{N}-\mathrm{CNTs}$ catalysts synthesized by impregnation and homogeneous precipitation methods. The bamboo-like N-CNTs were found to affect the formation of electron-deficient platinum, showing a 3-4 fold higher activity in formic acid decomposition when compared to the metallic platinum nanoparticles. A comparative study of platinum deposited on bamboo-like N-CNTs and herring-bone N-CNFs revealed that pyridinic nitrogen plays a key role in enhancing the activity of the catalysts irrespective of the structural features of the carbon nanomaterial.

\section{Materials and Methods}

Nitrogen-free carbon nanotubes (CNTs) and bamboo-like nitrogen-doped N-CNTs were grown on an $\mathrm{Fe}-\mathrm{Ni}$-containing catalyst $\left(62 \% \mathrm{Fe}-8 \% \mathrm{Ni}-30 \% \mathrm{Al}_{2} \mathrm{O}_{3}\right)$ via decomposition of ethylene or $40 \%$ ethylene- $60 \%$ ammonia mixture at $700{ }^{\circ} \mathrm{C}$ in a flow reactor with a fluidized catalyst bed [16]. Synthesized CNTs and N-CNTs were thoroughly washed to remove the growth catalyst first in concentrated $\mathrm{HCl}$, then boiled in $2 \mathrm{M} \mathrm{HCl}$ for $6 \mathrm{~h}$, and washed in distilled water until no chloride ions were detected in the rinsing liquid. The washed carbons were dried in $\mathrm{Ar}$ at $170{ }^{\circ} \mathrm{C}$ for $2 \mathrm{~h}$.

Platinum (0.2 and $1 \mathrm{wt} \%$ ) was deposited on the CNTs and N-CNTs by incipient wetness impregnation and homogeneous precipitation techniques using $\mathrm{H}_{2} \mathrm{PtCl}_{6}$ as the precursor. In the incipient wetness impregnation method, the defined volume of the $\mathrm{H}_{2} \mathrm{PtCl}_{6}$ aqueous solution was added to the freshly dried CNTs or N-CNTs at room temperature, the sample was thoroughly stirred, 
stored in a closed vessel for $30 \mathrm{~min}$, and then dried in air for $24 \mathrm{~h}$. The volume of the $\mathrm{H}_{2} \mathrm{PtCl}_{6}$ solution was defined based on the water capacity of the CNTs and N-CNTs [17]. The samples were designated as $0.2-2 \% \mathrm{Pt} / \mathrm{CNTs}-\mathrm{im}$ and $0.2-2 \% \mathrm{Pt} / \mathrm{N}-\mathrm{CNTs}-\mathrm{im}$. In the homogeneous precipitation technique, a known amount of $\mathrm{H}_{2} \mathrm{PtCl}_{6}$ was added to an aqueous suspension of the CNTs or N-CNTs and stirred for $60 \mathrm{~min}$ at room temperature. Then, a stoichiometric amount of $0.5 \mathrm{M}$ solution of $\mathrm{NaOH}$ was added dropwise at room temperature. The mixture was stirred and heated for $1.5 \mathrm{~h}$ at $70{ }^{\circ} \mathrm{C}$. Ultimately, the $\mathrm{pH}$ reached 8. The precipitates were filtered, carefully washed with distilled water, and dried in air. The samples were designated as $0.2-2 \% \mathrm{Pt} / \mathrm{CNTs}-\mathrm{pr}$ and $0.2-2 \% \mathrm{Pt} / \mathrm{N}-\mathrm{CNTs}-\mathrm{pr}$. Samples prepared by both methods were reduced in a 30 vol.\% $\mathrm{H}_{2} / \mathrm{Ar}$ mixture for $1 \mathrm{~h}$ at $250{ }^{\circ} \mathrm{C}$. The content of $\mathrm{Pt}$ in the catalysts was determined by $\mathrm{x}$-ray fluorescence spectroscopy.

Chemisorption measurements were made using a pulse technique and $\mathrm{CO}$ as the adsorbate at room temperature. Before the chemisorption measurements, the catalysts were re-reduced in situ in flowing hydrogen at $100{ }^{\circ} \mathrm{C}$. The fractions of metal atoms exposed $\left(\mathrm{Pt}_{\text {surface }} / \mathrm{Pt}_{\text {total }}\right)$ were calculated by assuming that the stoichiometry of adsorption $\mathrm{CO} / \mathrm{Pt}_{\text {surface }}$ was equal to 1 .

High-angle annular dark-field (HAADF STEM) images were obtained on a JEM-2200FS electron microscope at an accelerating voltage of $200 \mathrm{kV}$ using a high angle annular dark field (HAADF) detector in the scanning-TEM (STEM) mode.

X-ray photoelectron spectroscopy study was performed with an ES-300 (KRATOS Analytical) photoelectron spectrometer at a constant pass energy of a photoelectron energy analyzer. The spectra were recorded using an AlK $\alpha$ source with a quantum energy of $1486.6 \mathrm{eV}$. The energy scale was calibrated against the binding energy of gold $\mathrm{Au} 4 \mathrm{f}_{7 / 2}$ (equal to $84.0 \mathrm{eV}$ ) and copper $\mathrm{Cu} 2 \mathrm{p}_{3 / 2}$ (equal to $932.7 \mathrm{eV}$ ) [18]. The qualitative control of the surface chemical composition was made using the survey spectra in the range of $0-1100 \mathrm{eV}$ with the analyzer pass energy $\mathrm{HV}=50 \mathrm{eV}$ and scan step $1 \mathrm{eV}$. To analyze the quantitative composition and chemical state of elements, core levels of elements were recorded (Pt4f, Al2p, Cl2p, C1s, O1s, N1s, and Fe2p) at the analyzer pass energy of $\mathrm{HV}=25 \mathrm{eV}$ and scan step of $0.1 \mathrm{eV}$. Since the Pt $4 \mathrm{f}$ and Al2p lines overlap, control recording of the Pt $4 \mathrm{f}+\mathrm{Al} 2 \mathrm{p}$ spectral region for the CNTs and N-CNTs supports was performed to take into account a possible contribution of the Al2p line of aluminum from the growth catalyst to the Pt $4 \mathrm{f}$ spectrum of platinum. Prior to the experiments, the samples were treated ex situ with hydrogen at $250^{\circ} \mathrm{C}$ for $1 \mathrm{~h}$.

Experiments on formic acid decomposition ( $5 \mathrm{vol} . \% \mathrm{HCOOH} / \mathrm{He}$ ) were performed in a flow set-up using a quartz reactor with the inner diameter of $6 \mathrm{~mm}$. The catalyst loading was $20 \mathrm{mg}$; the catalyst powder was uniformly mixed with $0.5 \mathrm{~cm}^{3}$ of quartz sand (fraction $0.25-0.5 \mathrm{~mm}$ ). The reaction mixture feed rate was $20 \mathrm{~cm}^{3} / \mathrm{min}$. The experiments were carried out in the temperature-programmed mode, the temperature being raised at a rate of $2 \mathrm{deg} / \mathrm{min}$, and with chromatographic analysis of the gas mixture. The temperature of the reactor was measured using a thermocouple placed in the catalyst bed. All gas lines were preheated in a special box to $100^{\circ} \mathrm{C}$, whereas the reactor placed in the furnace had a special zone where the incoming gas was preheated to the reaction temperature.

The turnover frequencies (TOF) of the $1 \% \mathrm{Pt} / \mathrm{CNTs}-\mathrm{pr}$ and bamboo-like $1 \% \mathrm{Pt} / \mathrm{N}-\mathrm{CNTs}-\mathrm{pr}$ were compared with the TOFs of Pt catalysts deposited on the herring-bone carbon nanofibers $(1 \% \mathrm{Pt} / \mathrm{N}-\mathrm{CNFs})$. The properties of the $1 \% \mathrm{Pt} / \mathrm{N}-\mathrm{CNFs}$ catalysts were described in our previous article [19]. The TOF values for $1 \% \mathrm{Pt} / \mathrm{N}-\mathrm{CNF}$ catalysts for $125^{\circ} \mathrm{C}$ were calculated using the experimental data presented in [19].

\section{Results and Discussion}

Temperature dependences of the FA conversion on carbon supports and on supported Pt catalysts synthesized by homogeneous precipitation route are displayed in Figure 1. One can see that CNTs and N-CNTs possess some intrinsic activity, which is a typical for carbon nanomaterials [20-24]. The deposition of $0.2 \mathrm{wt} \%$ platinum on both supports shifted the temperature curve of conversion toward low temperatures by more than $100^{\circ} \mathrm{C}$. Note that a greater shift was observed in the case of $0.2 \% \mathrm{Pt} / \mathrm{N}-\mathrm{CNTs}$, which indicates differences in the properties of deposited platinum when going from 
$\mathrm{CNTs}$ to N-CNTs. The enhancement of the activity of N-doped catalysts when compared to N-free catalysts became even more pronounced if $1 \mathrm{wt} \%$ of $\mathrm{Pt}$ was deposited on the carbon nanotubes, as seen in Figure $1 b$.

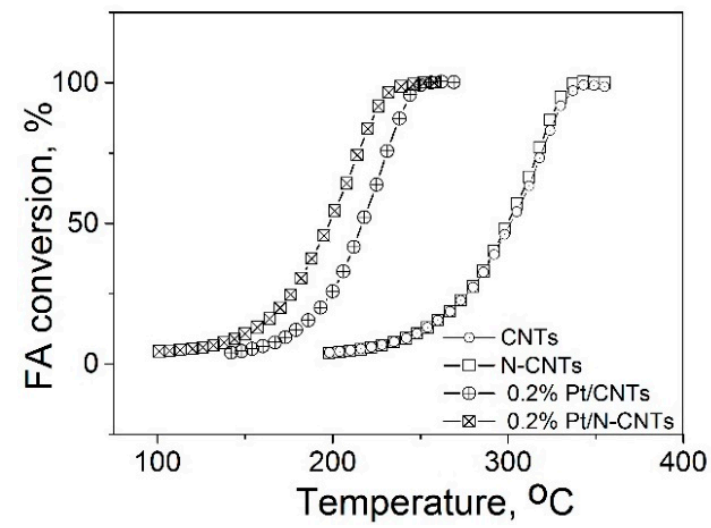

(a)

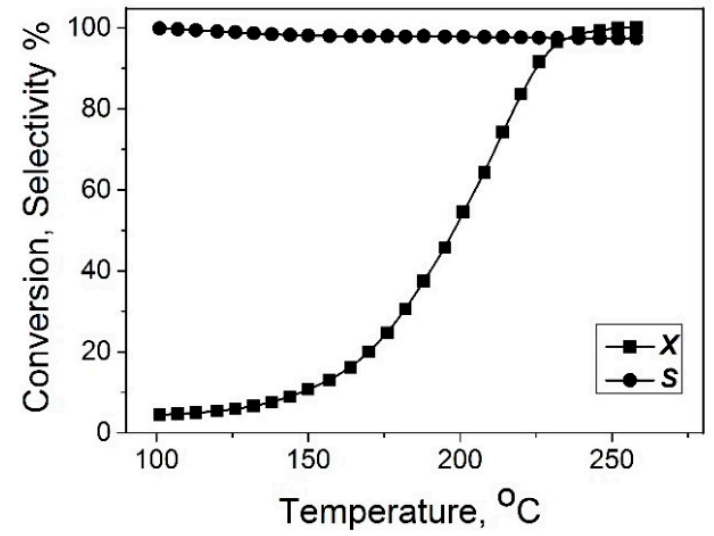

(c)

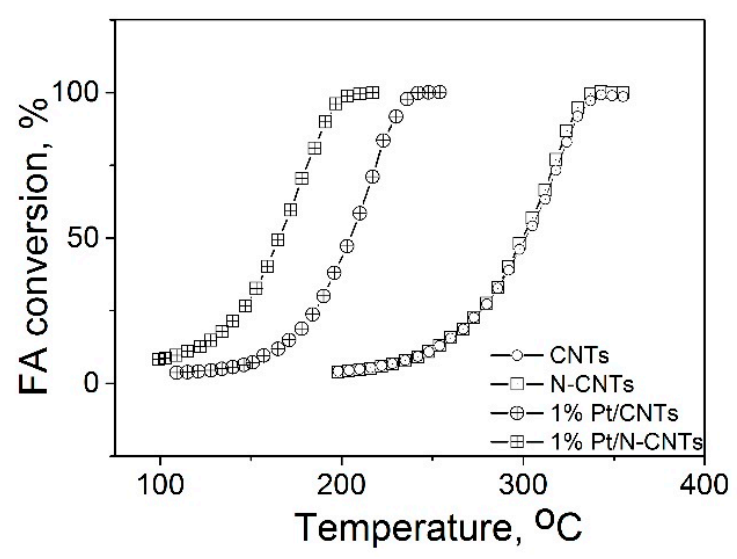

(b)

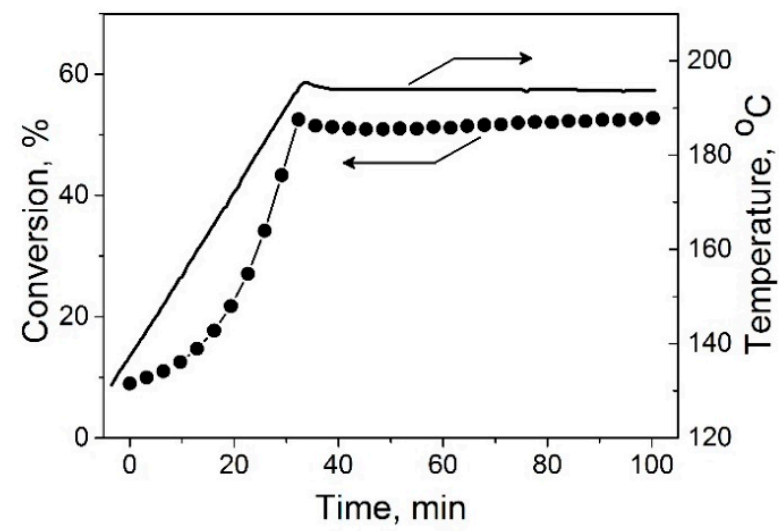

(d)

Figure 1. Temperature dependences of FA conversion on the CNTs, N-CNTs, and supported Pt catalysts synthesized by the homogeneous precipitation route: $0.2 \% \mathrm{Pt}(\mathbf{a})$ and $1 \% \mathrm{Pt}(\mathbf{b})$. Temperature dependences of FA conversion and selectivity on $0.2 \% \mathrm{Pt}-\mathrm{N}-\mathrm{CNTs}-\mathrm{pr}$ (c) and stability test of the $0.2 \% \mathrm{Pt}-\mathrm{N}-\mathrm{CNTs}-\mathrm{im}$ in the course of the reaction $(\mathrm{d})$.

It should also be noted that the promoting effect of N-CNTs when compared to CNTs was observed irrespective of the deposition method (impregnation or homogeneous precipitation). In all cases, the TOF values for $\mathrm{N}$-doped catalysts exceeded the TOFs for $\mathrm{N}$-free catalysts by a factor of 3-4 (Figure 2). One can also see that the increase in TOF was accompanied by a substantial increase in the selectivity toward hydrogen formation, from 92.6 to $98 \%$; this means a decrease of the CO content by $\sim 4$ times, where the latter is very important when FA is used for hydrogen production. Earlier, for the N-CNFs based catalysts, we demonstrated by DFT calculations that single metal ions coordinated by pyridinic nitrogen sites caused the cleavage of the $\mathrm{C}-\mathrm{H}$ bond in the FA molecule to give adsorbed hydrogen atom and carboxyl fragments [5]. It was demonstrated that the adsorbed hydrogen atom and hydrogen of the carboxyl fragment were directed toward each other, thus providing an easy formation of hydrogen and $\mathrm{CO}_{2}$.

At present, the improved properties of metal catalysts supported on various $\mathrm{N}-\mathrm{CNMs}$ are attributed to a decrease in the particle size or an increase/decrease in the electron density of metals due to MSI via nitrogen species or defects consisting of carbon vacancies and nitrogen sites [25,26]. Indeed, since the specific areas of all of our catalysts measured by Brunauer-Emmett-Teller method varied in a very narrow range (140-150 $\left.\mathrm{m}^{2} / \mathrm{g}\right)$, the observed differences were most likely related to differences in the properties of the deposited platinum. To verify this hypothesis, various characteristics of deposited 
platinum were analyzed; first, sizes of the platinum particles in the supported catalysts were compared. For this purpose, we used chemisorption of $\mathrm{CO}$, which is sensitive to the dispersion of metals $[27,28]$ as well as HAADF STEM.

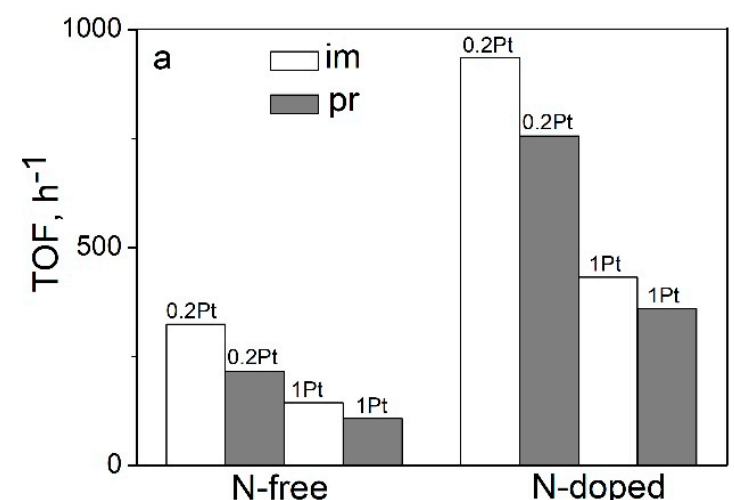

(a)

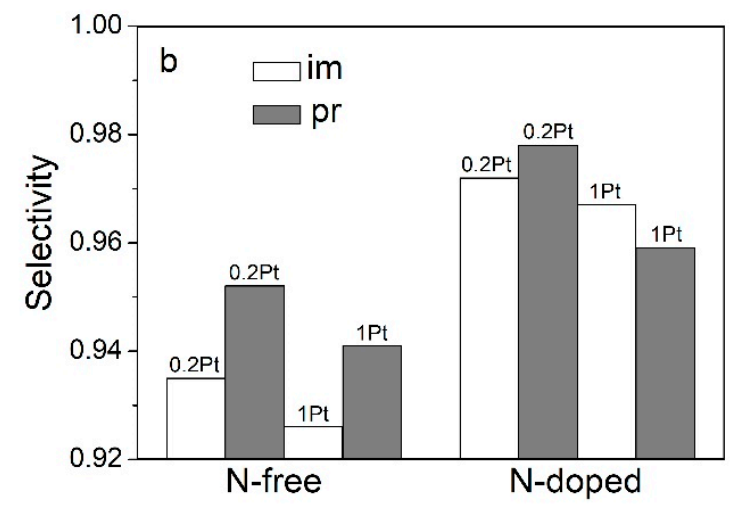

(b)

Figure 2. TOF values of the FA decomposition at $125{ }^{\circ} \mathrm{C}$ (a) and selectivity at $50 \%$ FA conversion (b) on the Pt catalysts deposited on CNTs and N-CNTs by different routes: im-impregnation, pr-homogeneous precipitation.

As seen in Figure 3, a minor increase in the TOF with an increase in the $\mathrm{CO} / \mathrm{Pt}$ ratio was observed for the $\mathrm{N}$-free catalysts, which may be assigned to similar dispersions of deposited metallic platinum in the tested catalysts $[27,28]$. In the case of $\mathrm{N}$-doped catalysts, an inverse dependence was observed: TOF decreases with increases in the $\mathrm{CO} / \mathrm{Pt}$ value. In addition, for this series of samples, a decrease in the platinum content from 1 to $0.2 \%$ was accompanied by a considerable (nearly 3 -fold) decrease in the $\mathrm{CO} / \mathrm{Pt}$ value, irrespective of the platinum deposition method. Such a pronounced decrease in the amount of chemisorbed CO by lowering the concentration of the deposited metal from 2 to $0.2 \mathrm{wt} \%$ was observed in our earlier study for the $\mathrm{Pd} / \mathrm{N}-\mathrm{CNTs}$ catalysts; a possible reason is that the catalysts with a palladium content $<0.8 \mathrm{wt} \%$ completely consisted of isolated palladium ions, which poorly chemisorb CO [12].

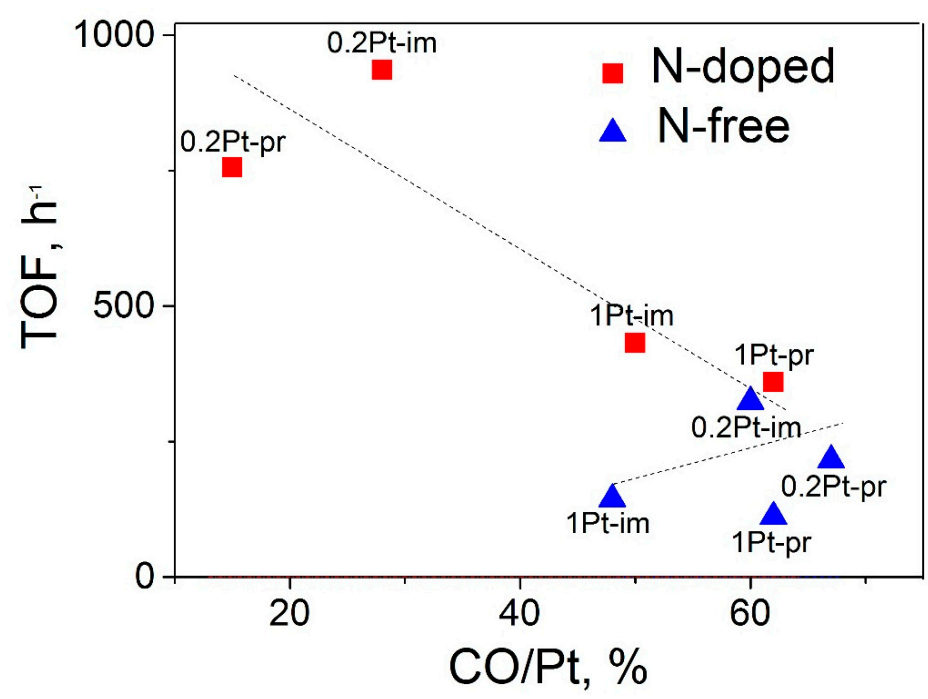

Figure 3. The influence of TOF of formic acid decomposition at $125{ }^{\circ} \mathrm{C}$ on the $\mathrm{CO} / \mathrm{Pt}$ ratio for the $\mathrm{N}$-doped and $\mathrm{N}$-free catalysts differing in $\mathrm{Pt}$ content and preparation route: im-impregnation, pr-homogeneous precipitation. 
To verify this assumption, the catalysts were studied by HAADF STEM. It was found that the most active catalyst $0.2 \% \mathrm{Pt} / \mathrm{N}-\mathrm{CNTs}-\mathrm{im}$ consisted of Pt particles with the size of about $1.1 \mathrm{~nm}$ and a narrow size distribution, whereas the lowest active 1\%Pt/CNTs-pr contained nanoparticles of $\sim 1.9 \mathrm{~nm}$ with a wider size distribution (Table 1). Meanwhile, the size of the nanoparticles in all samples, irrespective of the support type, deposition method, and Pt content, changed in a quite narrow range of 1.1-1.9 nm, which cannot explain such strong differences in the CO/Pt values from 15 to $67 \%$ (Figure 3). Therefore, it can be supposed that the catalysts contain platinum clusters or atoms/ions besides nanoparticles. Indeed, the presence of such species was discovered in all catalysts. The most representative photos of the catalysts showing single atoms are given in Figure 4. However, in the N-doped catalysts, the quantity of the isolated platinum atoms was found to be considerably higher, and these atoms were distributed on the N-CNT surface uniformly when compared with $\mathrm{N}$-free catalysts.

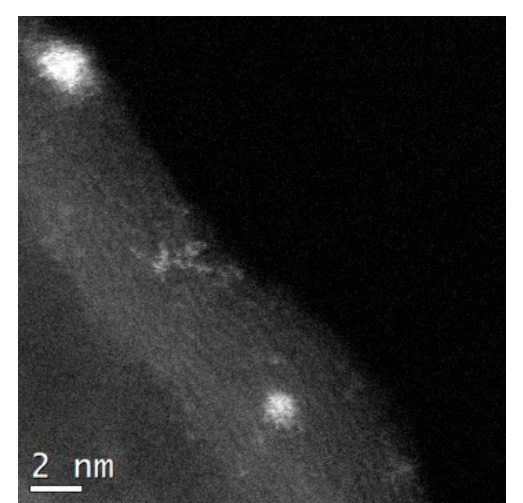

(a)

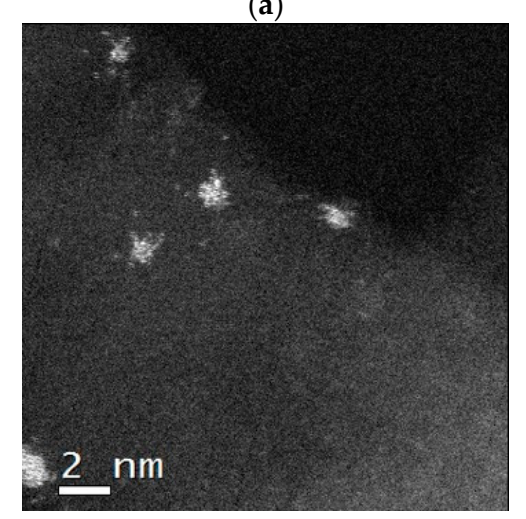

(c)

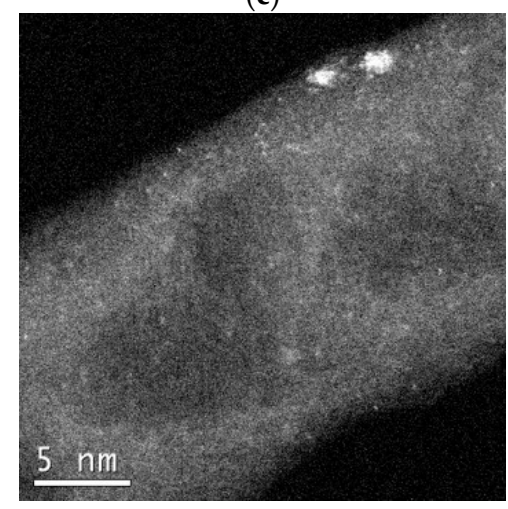

(e)

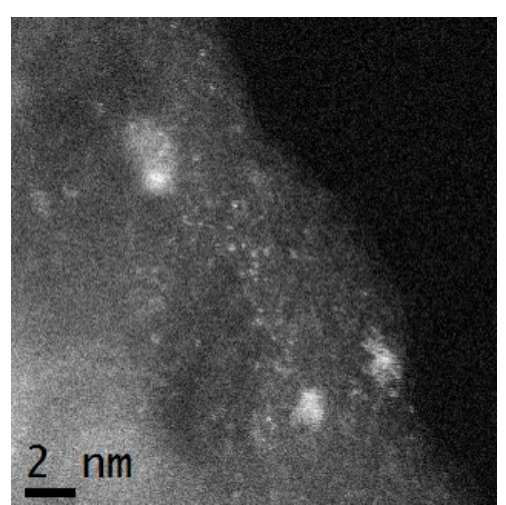

(b)

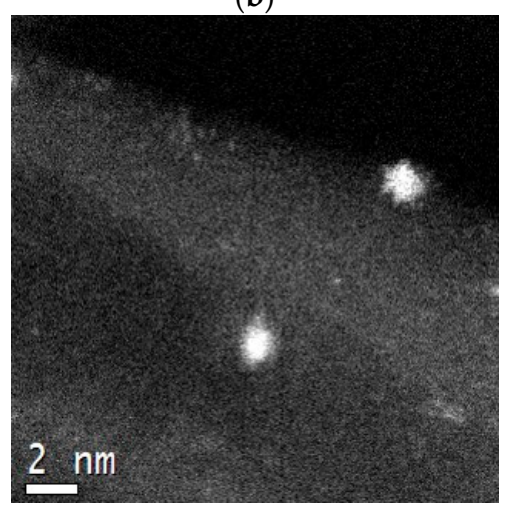

(d)

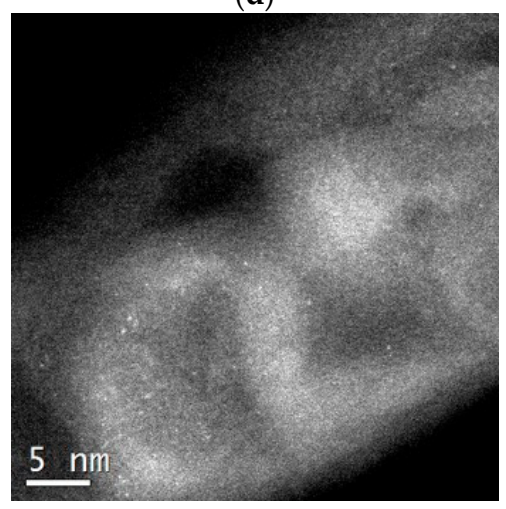

(f)

Figure 4. HAADF STEM images of 1\%Pt/CNTs-imp (a), 1\%Pt/N-CNTs-imp (b), 1\%Pt/CNTs-pr (c), $1 \% \mathrm{Pt} / \mathrm{N}-\mathrm{CNTs}-\mathrm{pr}(\mathbf{d}), 0.2 \% \mathrm{Pt} / \mathrm{N}-\mathrm{CNTs}-\mathrm{imp}(\mathbf{e})$, and $0.2 \% \mathrm{Pt} / \mathrm{N}-\mathrm{CNTs}-\mathrm{pr}(\mathbf{f})$. 
Table 1. HAADF STEM platinum nanoparticle size (nm), standard deviation (sd), $\mathrm{TOF}\left(\mathrm{h}^{-1}\right)$ at $125{ }^{\circ} \mathrm{C}$.

\begin{tabular}{cccc}
\hline Catalyst & Pt Size, $\mathbf{n m}$ & sd & TOF, $\mathbf{h}^{\mathbf{- 1}}$ \\
\hline 1\%Pt/CNTs-im & 1.3 & 0.4 & 144 \\
1\%Pt/CNTs-pr & 1.9 & 0.7 & 108 \\
0.2\%Pt/CNTs-im & 1.2 & 0.3 & 324 \\
0.2\%Pt/CNTs-pr & 1.3 & 0.5 & 216 \\
1\%Pt/N-CNTs-im & 1.4 & 0.4 & 432 \\
1\%Pt/N-CNTs-pr & 1.3 & 0.3 & 360 \\
$0.2 \% \mathrm{Pt} / \mathrm{N}-\mathrm{CNTs}-\mathrm{im}$ & 1.1 & 0.2 & 936 \\
$0.2 \% \mathrm{Pt} / \mathrm{N}-\mathrm{CNTs}-\mathrm{pr}$ & 1.6 & 0.4 & 756 \\
\hline
\end{tabular}

Thus, it can be concluded that both methods of platinum deposition on CNTs and N-CNTs can produce dispersed catalysts consisting of nanoparticles and isolated platinum atoms. For the $\mathrm{N}$-free catalysts, the samples mainly consisted of nanoparticles and quite a low quantity of single atoms, which did not significantly influence the $\mathrm{CO} / \mathrm{Pt}$ and TOF values (Figure 3). For the $\mathrm{N}$-doped catalysts, irrespective of their preparation procedure, a decrease in the platinum content strongly lowered the $\mathrm{CO} / \mathrm{Pt}$ ratio and increased the $\mathrm{TOF}$ in $\mathrm{HCOOH}$ decomposition and the selectivity of hydrogen formation.

Along with this, of note is a slightly higher activity of the catalysts obtained by incipient wetness impregnation when compared to the catalysts synthesized by homogeneous precipitation, irrespective of the support type and platinum content (Figure 2). The observed difference for the $\mathrm{N}$-free catalysts can be attributed to a larger particle size and a broader particle size distribution of the catalysts obtained by homogeneous precipitation (Table 1). In the case of the impregnation method, platinum particles were formed directly from $\left[\mathrm{PtCl}_{6}\right]^{2-}$ anions that were molecularly adsorbed on the carbon surface. In homogeneous precipitation from aqueous solutions, hydrolysis can lead to the formation of not only mono-, but also polynuclear platinum complexes $\left[\mathrm{Pt}(\mathrm{OH})_{\mathrm{x}} \mathrm{O}_{\mathrm{y}}\right]_{\mathrm{n}}$ and hence to the formation of larger platinum particles with different sizes [27]. For the N-doped catalysts, the situation seems to be more complicated and in this case, the MSI between the Pt and nitrogen groups should similarly be taken into account like in [8]. However, the homogeneous precipitation method is preferable because it has no scaling limitations.

The difference between $\mathrm{N}$-free and $\mathrm{N}$-doped catalysts can also be seen in the XPS spectra. Figure 5a shows an example for $0.2 \% \mathrm{Pt} / \mathrm{CNTs}-\mathrm{pr}$ and $0.2 \% \mathrm{Pt} / \mathrm{N}-\mathrm{CNTs}-\mathrm{pr}$ samples. In the case of $0.2 \% \mathrm{Pt} / \mathrm{N}-\mathrm{CNTs}-\mathrm{pr}$, the Pt $4 \mathrm{f}$ line shifted toward higher binding energies by ca. $0.3 \mathrm{eV}$. The difference spectrum shows a doublet with $\mathrm{E}_{\mathrm{b}}\left(\mathrm{Pt}_{4 \mathrm{f}} \mathrm{f/2}\right)=72.9 \mathrm{eV}$, which indicates the presence of two or more $\mathrm{Pt}$ states in the catalysts. Deconvolution of Pt4f spectra into individual doublets allowed us to find the $\mathrm{E}_{\mathrm{b}}\left(\mathrm{Pt}_{4 \mathrm{f}_{7 / 2}}\right)$ value and the contribution of different components to the experimental spectrum (Figure $5 \mathrm{~b}$ ).

Three states with $\mathrm{E}_{\mathrm{b}}\left(\mathrm{Pt}_{4 \mathrm{f}} / 2\right)=71.7,72.9$, and $74.2 \mathrm{eV}$ can be distinguished in the Pt4f spectra (Figure $5 b)$. The peak with $\mathrm{E}_{\mathrm{b}}\left(\mathrm{Pt} \mathrm{f}_{7 / 2}\right)=71.7 \mathrm{eV}$ corresponds to metallic platinum particles $\mathrm{Pt}^{0}$. A small increase in $\mathrm{E}_{\mathrm{b}}\left(\mathrm{Pt}_{\mathrm{t}} \mathrm{f}_{7 / 2}\right)$ with respect to the value typical of bulk metallic platinum (71.1 eV) [18] indicates the formation of small nanoparticles $[29,30]$ and is related to the photoemission relaxation effect [31,32]. The peak with the binding energy of $74.2 \mathrm{eV}$ can be assigned to the oxidized platinum species $\mathrm{Pt}^{4+}[33,34]$. The oxidized platinum species may emerge due to the oxidation of nanoparticles when samples make contact with the atmosphere during the transfer to the spectrometer. The peak with the binding energy of $72.9 \mathrm{eV}$ can be attributed to the oxidized platinum species $\mathrm{Pt}^{2+}$ [29] as well as to the atomically dispersed platinum species [35-37]. As seen in Figure $5 b$, when going from CNTs to N-CNTs, a relative contribution of the platinum species with $\mathrm{E}_{\mathrm{b}}\left(\mathrm{Pt}_{\mathrm{t}} \mathrm{f}_{7 / 2}\right)=72.9 \mathrm{eV}$ increases from 30 to $42 \%$, which testifies to the formation of more dispersed or oxidized platinum species in this sample. Taking into account that this catalyst virtually does not chemisorb $\mathrm{CO}(\mathrm{CO} / \mathrm{Pt}=15)$, it can be supposed that in $\mathrm{N}$-doped catalysts, along with metallic platinum, the electron-deficient platinum is present. The electron-deficient platinum can be formed as $\mathrm{Pt}^{2+}$ species at the interfaces of Pt nanoparticles and N-CNTs [38] and isolated Pt ions. 
According to the DFT calculations, the formation of such electron-deficient metal species may occur due to the interaction of metals with pyridinic sites of various $\mathrm{N}-\mathrm{CNMs}$ [5,7-11].

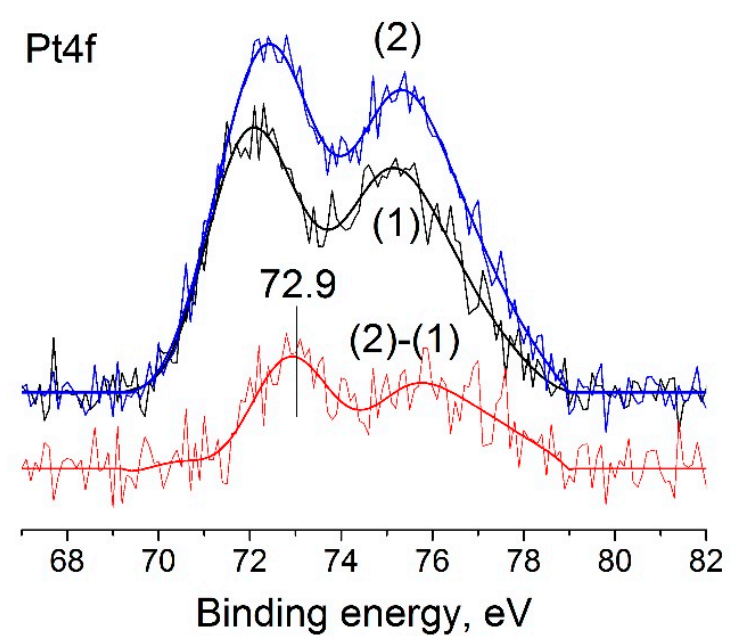

(a)

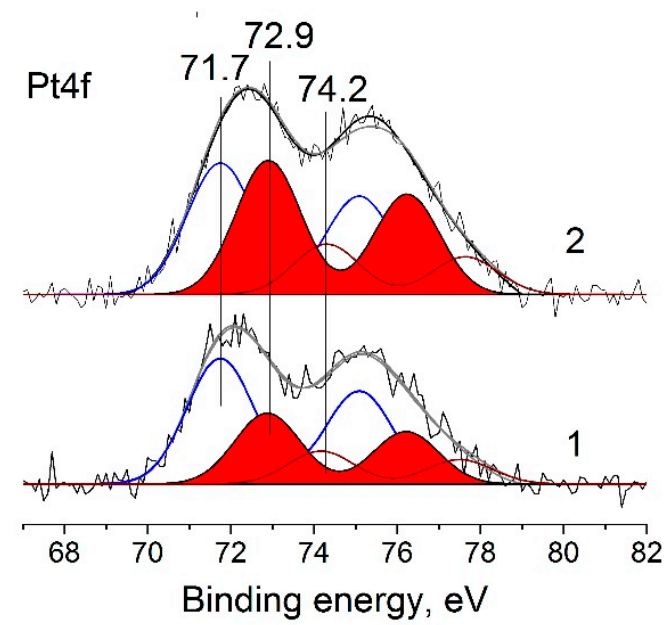

(b)

Figure 5. (a) Pt4f spectra and (b) curve-fitted Pt4f spectra of $0.2 \% \mathrm{Pt} / \mathrm{CNTs}-\mathrm{pr}$ (1) and $0.2 \% \mathrm{Pt} / \mathrm{N}-\mathrm{CNTs}-\mathrm{pr}$ (2) catalysts.

To confirm the interaction of metals with certain nitrogen sites of $\mathrm{N}-\mathrm{CNMs}$, a detailed analysis of the XPS spectra of deposited metal and nitrogen is commonly used. In [39], the $\mathrm{E}_{\mathrm{b}}\left(\mathrm{Pt}_{4 \mathrm{f}} \mathrm{f/2}\right)$ shift to a lower level was assigned to the interaction of Pt nanoparticles with nitrogen centers of the CN@Pt/CNTs catalyst. In [40], the depth of XPS analysis decreased when using the energy of monochromatized synchrotron radiation at $800 \mathrm{eV}$; this allowed the authors to observe a decrease in the intensity of the pyridinic nitrogen line and the appearance of a new line at $398.7 \mathrm{eV}$, which was assigned to the interaction of Pd with pyridinic sites of the $\mathrm{N}-\mathrm{C}_{\mathrm{M}}$ material. Although in [41] the XPS experiments were performed at a high energy of $\mathrm{x}$-ray radiation, $\mathrm{ca} .1500 \mathrm{eV}$, the authors observed a shift in the graphitic nitrogen peak to the high energy side by $0.2 \mathrm{eV}$ upon Pt deposition on N-CNTs. It should be noted that the N-CNTs were synthesized by post-treatment of the oxidized CNTs with ammonia, and nitrogen seems to be located most likely only on the tube surface. In [8], simultaneous changes were observed in positions of the lines corresponding to both the graphitic and pyridinic nitrogen upon platinum deposition on $\mathrm{N}-\mathrm{CNTs}$, depending on the synthesis method and platinum amount; nevertheless, it was concluded that only one of the nitrogen species was responsible for stabilization.

In our study, we primarily verified that nitrogen was incorporated into the carbon's structure: this was indicated by the $0.4 \mathrm{eV}$ shift of the $\mathrm{C} 1 \mathrm{~s}$ spectrum relative to the position typical of $\mathrm{sp}^{2}$-hybride carbon structures $(284.4 \mathrm{eV}$ ) and by broadening of the line toward high energies (Figure 6a) [42,43]. The analysis of the N1s spectra revealed that the main structural forms of nitrogen observed in $\mathrm{N}-\mathrm{CNMs}$ are present in N-CNTs: pyridinic $\left(\mathrm{N}_{\mathrm{Py}} 398.5 \mathrm{eV}\right)$, pyrrolic $\left(\mathrm{N}_{\mathrm{Pyr}} 399.6 \mathrm{eV}\right)$, and graphitic $\left(\mathrm{N}_{\mathrm{Q}} 401.0 \mathrm{eV}\right)[9,43,44]$. Peaks in the region of 402.5 and $404.7 \mathrm{eV}$ correspond to the oxidized state and molecular nitrogen encapsulated inside the N-CNTs (Figure $6 \mathrm{~b}$ ).

A comparison of the N1s spectra for $\mathrm{N}-\mathrm{CNTs}$ and $0.2 \% \mathrm{Pt} / \mathrm{N}-\mathrm{CNTs}-\mathrm{pr}$, which is illustrated in Table 2, did not allow a reliable conclusion on the type of nitrogen involved in platinum anchoring. Investigation of samples with the platinum content of $1 \mathrm{wt} \%$ also did not clear up this question. All of the recorded differences were within the measurement error, although a slight decrease in the $\mathrm{N}_{\mathrm{Py}}$ content upon increase in the Pt concentration in the catalysts was observed. Thus, it can be stated that the possibilities of XP spectroscopy used in this study make it possible to reliably conclude only on an increase in the relative amount of platinum with $\mathrm{E}_{\mathrm{b}}\left(\mathrm{Pt}_{\mathrm{f}} \mathrm{f}_{7 / 2}\right)=72.9 \mathrm{eV}$ in N-doped catalysts. Sensitivity of the methods should be increased considerably to make a reliable and detailed 
interpretation of the changes that occur in the N1s spectra upon platinum deposition on N-CNTs, in which, as we have shown, nitrogen is distributed uniformly in the bulk of the material [15].

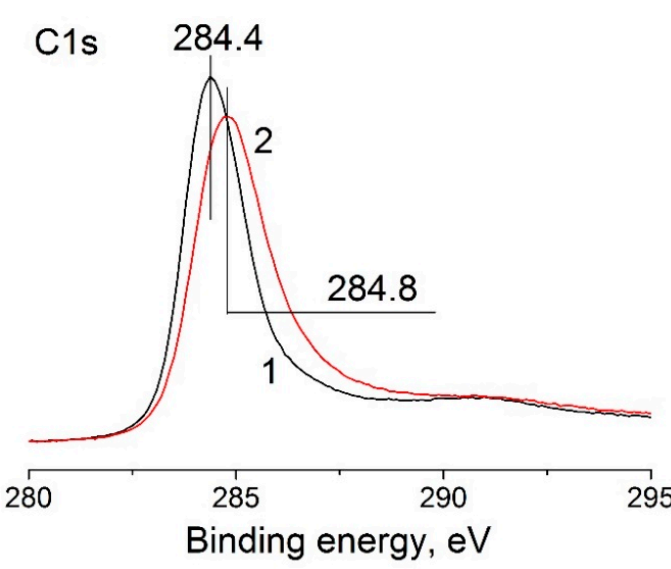

(a)

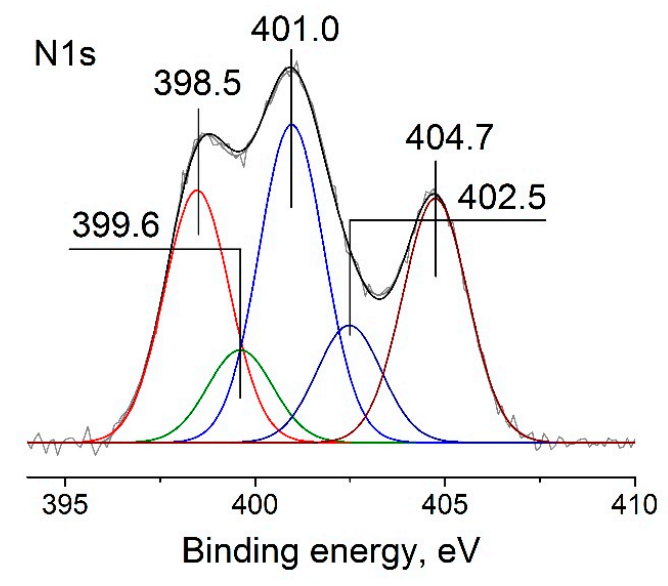

(b)

Figure 6. C1s (a) of $0.2 \% \mathrm{Pt} / \mathrm{CNTs}-\mathrm{pr}(1)$ and $0.2 \% \mathrm{Pt} / \mathrm{N}-\mathrm{CNTs}-\mathrm{pr}(2)$ catalysts and N1s (b) XPS spectra of $0.2 \% \mathrm{Pt} / \mathrm{N}-\mathrm{CNTs}-\mathrm{pr}$ catalyst.

Table 2. Content of different nitrogen species according to XPS data.

\begin{tabular}{|c|c|c|c|c|c|c|c|c|c|c|c|}
\hline \multirow[t]{2}{*}{ Sample } & \multicolumn{2}{|c|}{$\mathbf{N}_{\mathbf{P y}}$} & \multicolumn{2}{|c|}{$\mathrm{N}_{\text {Pyr }}$} & \multicolumn{2}{|c|}{$\mathrm{N}_{\mathrm{Q}}$} & \multicolumn{2}{|c|}{$\mathrm{N}-\mathrm{Ox}$} & \multicolumn{2}{|c|}{$\mathbf{N}_{2}$} & \multirow{2}{*}{$\begin{array}{c}\mathrm{N} \\
\text { wt } \%\end{array}$} \\
\hline & $\mathbf{E b}$ & wt $\%$ & $\mathbf{E b}$ & wt $\%$ & $\mathbf{E b}$ & wt $\%$ & $\mathbf{E b}$ & wt $\%$ & $\mathbf{E b}$ & wt $\%$ & \\
\hline $\mathrm{N}-\mathrm{CNTs}$ & 398.4 & 1.4 & 399.6 & 0.50 & 401.0 & 1.75 & 402.5 & 0.60 & 404.7 & 1.35 & 5.6 \\
\hline $0.2 \% \mathrm{Pt} / \mathrm{N}-\mathrm{CNTs}-\mathrm{pr}$ & 398.4 & 1.35 & 399.6 & 0.50 & 401.0 & 1.70 & 402.5 & 0.70 & 404.7 & 1.35 & 5.6 \\
\hline $1 \% \mathrm{Pt} / \mathrm{N}-\mathrm{CNTs}-\mathrm{pr}$ & 398.4 & 1.30 & 399.5 & 0.50 & 400.9 & 1.70 & 402.3 & 0.65 & 404.7 & 1.35 & 5.5 \\
\hline
\end{tabular}

Finally, we compared the Pt catalysts deposited on the CNTs and bamboo-like N-CNTs with corresponding Pt catalysts deposited on herring-bone CNFs and N-CNFs. It should be noted that nitrogen-free and nitrogen-doped carbon nanotubes and nanofibers were synthesized by the same CVD method using ethylene or the standard ethylene-ammonia reaction mixture (see [19] and this work). Figure 7 shows the activity of these catalysts in the formic acid decomposition reaction. As seen in Figure 7, there was a rather good correlation between the TOF value and nitrogen content in the materials, irrespective of the essential differences in their structure related to the packing of graphene layers.

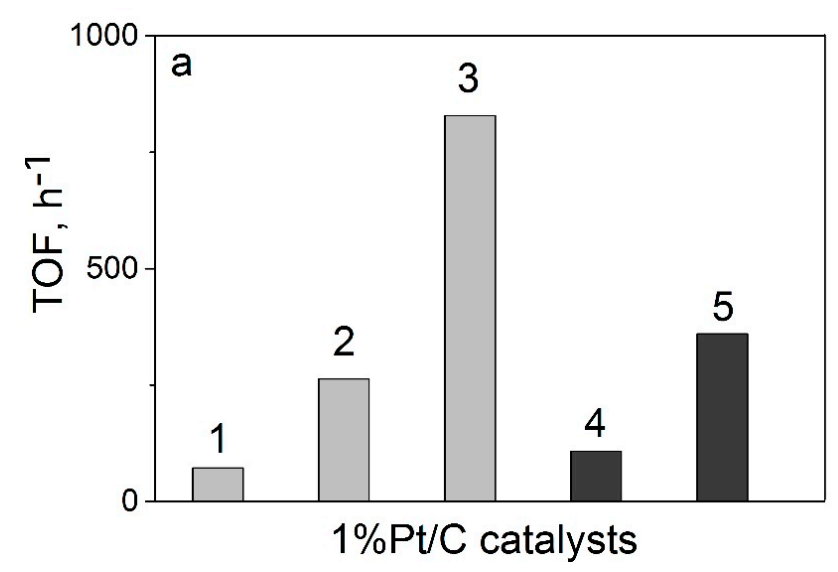

(a)

Figure 7. Cont. 


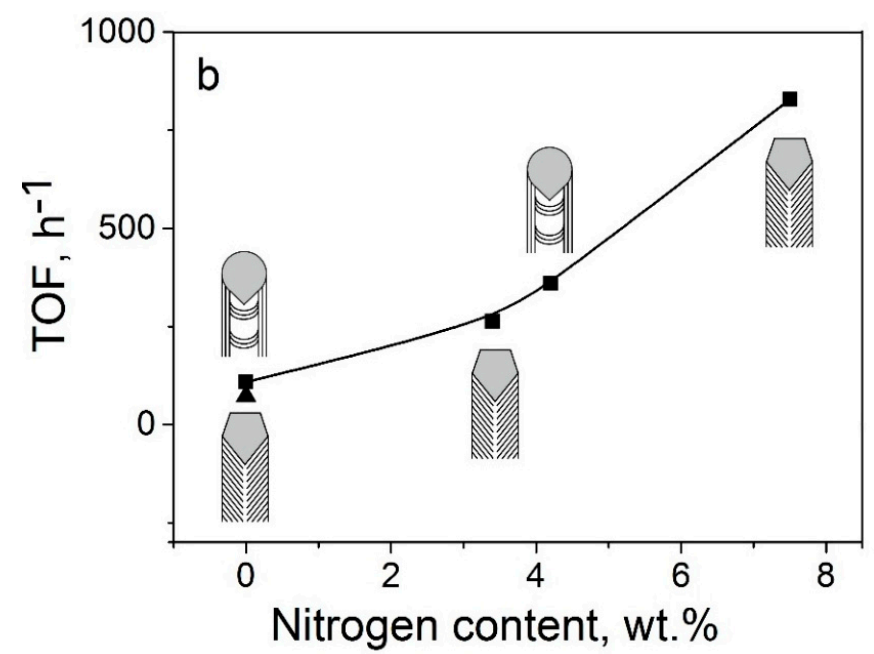

(b)

Figure 7. The TOF values at $125{ }^{\circ} \mathrm{C}$ for the $1 \% \mathrm{Pt} / \mathrm{C}$ catalysts synthesized by the homogeneous precipitation route depending on (a) carbon supports: $\mathrm{CNFs}(1), 3.4 \% \mathrm{~N}-\mathrm{CNFs}(2), 7.5 \% \mathrm{~N}-\mathrm{CNFs}(3)$, CNTs (4), 5.5\%N-CNTs (5); and (b) nitrogen content in the catalysts (for 5.5\%N-CNTs the capsulated $\mathrm{N}_{2}(1.35 \mathrm{wt} \%)$ was excluded). TOFs for $\mathrm{CNFs} / \mathrm{N}-\mathrm{CNFs}$-based catalysts were calculated using the data presented in [19].

Moreover, for the carbon tube- and carbon fiber-based catalysts, the decrease in the platinum content to $0.2-0.3 \mathrm{wt} \%$ led to the same dramatic decrease in the $\mathrm{CO} / \mathrm{Pt}$ values to an extremely low level $(<20 \%)$ and, on the contrary, to a substantial increase in TOF (see [5] and this work). The latter allowed us to conclude that pyridinic nitrogen also plays a key role in the formation of electron-deficient platinum in the case of N-CNTs. The amount of electron-deficient platinum depends on the content of pyridinic nitrogen, which in turn is known to be dependent on the total amount of nitrogen in $\mathrm{N}-\mathrm{CNTs}$ and N-CNFs [13]. The additional arguments in favor of this conclusion are the similar values of $\mathrm{E}_{\mathrm{b}}\left(\mathrm{Pt}_{4 \mathrm{f}} \mathrm{f/2}\right)$ for the catalysts with low platinum content, $0.2 \% \mathrm{Pt} / \mathrm{N}-\mathrm{CNTs}-\mathrm{pr}$, and $0.3 \% \mathrm{Pt} / \mathrm{N}-\mathrm{CNFs}$, showing the high activity in the FA decomposition reaction (Figure 8).

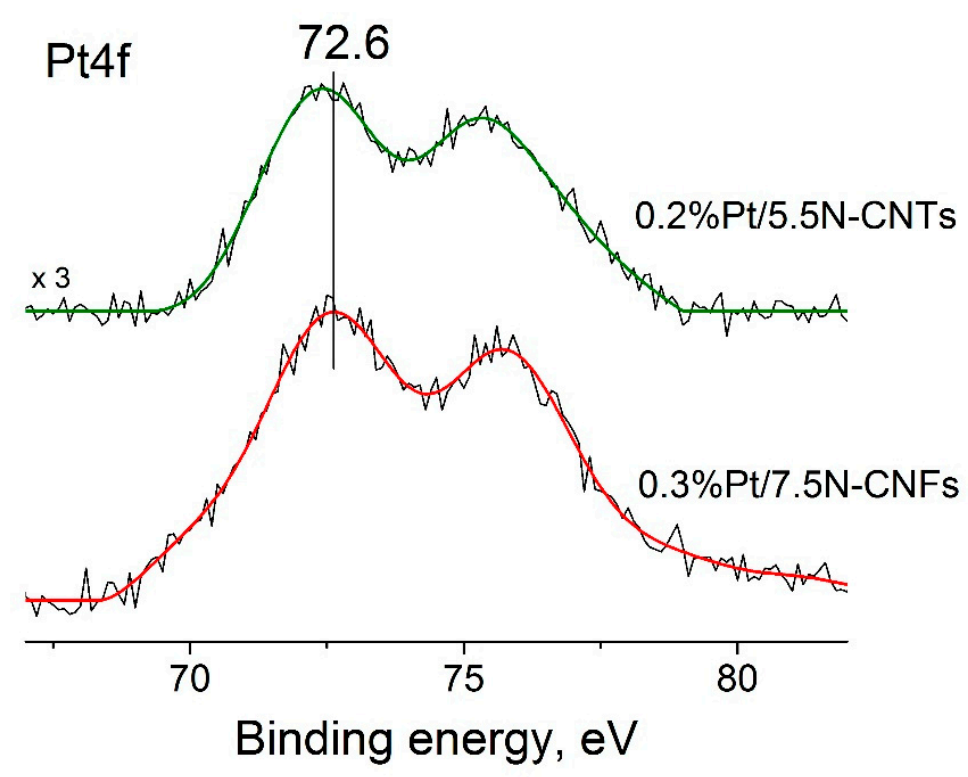

Figure 8. Pt4f spectra of the $0.3 \% \mathrm{Pt} / \mathrm{N}-\mathrm{CNFs}-\mathrm{pr}$ and $0.2 \% \mathrm{Pt} / \mathrm{N}-\mathrm{CNTs}-\mathrm{pr}$ catalysts. For $0.3 \% \mathrm{Pt} / \mathrm{N}-\mathrm{CNFs}-\mathrm{pr}$, the data presented in [19] were used. 
Indeed, metal species with high binding energies, which are typical of electron-deficient metals or single atoms stabilized by nitrogen sites, were observed in the case of $\mathrm{N}-\mathrm{CNMs}$ with different structures such as bamboo-like tubes [8,9,12], carbon nanofibers with a herring-bone structure [5], porous carbon materials $[6,7,45]$, or carbon nitride $[10,46]$. In the listed materials, nitrogen is present in all standard states (graphitic, pyrrolic, and pyridinic), which makes possible the locally one-type interaction of metals with nitrogen sites irrespective of their considerable structural differences. The authors of [8] explained the formation of electron-deficient platinum by the interaction of platinum with the acceptor defects containing pyridinic nitrogen and carbon vacancy. Such structural fragments of the graphene layer of $\mathrm{C}_{3} \mathrm{~N}_{4}$, as shown in $[10,46]$, also efficiently stabilizes the atomic palladium. This allows for a conclusion that, irrespective of the structural features of various N-CNMs, these materials have common properties concerning the interaction with metals; among them the formation of highly stable (Figure 1c,d) electron-deficient metal nanoparticles, isolated ions, or single atoms via the interaction with pyridinic nitrogen sites. The amount of these species depends on the content of pyridinic nitrogen, which in turn is usually determined by the total amount of nitrogen in various N-CNMs [13]. These species poorly chemisorb CO, but are highly active in the selective hydrogenation of acetylene, ammonia-borane hydrolysis, one-pot conversion of cellulose, and formic acid decomposition for the production of pure hydrogen. Thus, the possibility of controlling the size and electronic state of deposited metals makes a broad class of N-CNMs unique materials for the synthesis of efficient supported catalysts for different purposes.

\section{Conclusions}

The nitrogen species in $\mathrm{N}-\mathrm{CNTs}$ manifest themselves as efficient anchoring sites for both $\mathrm{Pt}$ nanoparticles and single atoms, irrespective of the method used for Pt deposition (impregnation or homogeneous precipitation). Nitrogen in N-CNTs favors the formation of electron-deficient platinum in comparison with $\mathrm{N}$-free carbon nanotubes. Moreover, it was shown that both the activity and selectivity of ionic platinum in the decomposition of formic acid were considerably higher when compared to Pt in the fully metallic state. The comparison of the results with those for $\mathrm{Pt} / \mathrm{N}-\mathrm{CNFs}$ and with the literature data for other metals and nitrogen-doped carbon supports of different structures allows us to conclude that the interaction between metal and nitrogen species has a general nature and the electron deficiency of the metal as well as the catalytic properties are mainly dependent on the concentration of pyridinic nitrogen.

Author Contributions: Conceptualization, O.P. and V.P.; Data curation, A.L. and A.B.; Investigation, O.P., A.L., L.K., A.B., O.S., V.Z., A.S., and V.S.; Methodology, O.P.; Supervision, V.P.; Writing-original draft, O.P.; Writing-review \& editing, A.L., L.K., A.B., and V.P.

Funding: This work was supported by the Russian Science Foundation (Grant No. 17-73-30032).

Conflicts of Interest: The authors declare no conflicts of interest.

\section{References}

1. Grasemann, M.; Laurenczy, G. Formic acid as a hydrogen source-Recent developments and future trends. Energy Environ. Sci. 2012, 5, 8171-8181. [CrossRef]

2. Singh, A.K.; Singh, S.; Kumar, A. Hydrogen energy future with formic acid: A renewable chemical hydrogen storage system. Catal. Sci. Tevhnol. 2016, 6, 12-40. [CrossRef]

3. Zhu, J.; Holmen, A.; Chen, D. Carbon nanomaterials in catalysis: Proton affinity, chemical and electronic properties, and their catalytic consequences. Chem CatChem 2013, 5, 378-401. [CrossRef]

4. Su, D.S.; Perathoner, S.; Centi, G. Nanocarbons for the development of advanced catalysts. Chem. Rev. 2013, 113, 5782-5816. [CrossRef]

5. Bulushev, D.A.; Zacharska, M.; Lisitsyn, A.S.; Podyacheva, O.Y.; Hage, F.S.; Ramasse, Q.M.; Bangert, U.; Bulusheva, L.G. Single atoms of Pt-group metals stabilized by N-doped carbon nanofibers for efficient hydrogen production from formic acid. ACS Catal. 2016, 6, 3442-3451. [CrossRef] 
6. Tang, C.; Surkus, A.; Chen, F.; Pohl, M.; Agostini, G.; Schneider, M.; Junge, H.; Beller, M. A stable nanocobalt catalyst with highly dispersed CoNx active sites for the selective dehydrogenation of formic acid. Angew. Chem. Int. Ed. 2017, 56, 16616-16620. [CrossRef] [PubMed]

7. Zacharska, M.; Bulusheva, L.G.; Lisitsyn, A.S.; Beloshapkin, S.; Guo, Y.; Chuvilin, A.L.; Shlyakhova, E.V.; Podyacheva, O.Y.; Leahy, J.L.; Okotrub, A.V.; et al. Factors influencing the performance of Pd/C catalysts in the green production of hydrogen from formic acid. ChemSusChem 2017, 10, 720-730. [CrossRef]

8. Ning, X.; Li, Y.; Dong, B.; Wang, H.; Yu, H.; Peng, F.; Yang, Y. Electron transfer dependent catalysis of Pt on N-doped carbon nanotubes: Effects of synthesis method on metal-support interaction. J. Catal. 2017, 348, 100-109. [CrossRef]

9. Arrigo, R.; Schuster, M.E.; Xie, Z.; Yi, Y.; Wowsnick, G.; Sun, L.L.; Hermann, K.E.; Friedrich, M.; Kast, P.; Hävecker, M.; et al. Nature of the N-Pd interaction in nitrogen-doped carbon nanotube catalysts. ACS Catal. 2015, 5, 2740-2753. [CrossRef]

10. Huang, X.; Xia, Y.; Cao, Y.; Zheng, X.; Pan, H.; Zhu, J.; Ma, C.; Wang, H.; Li, J.; You, R.; et al. Enhancing both selectivity and coking-resistance of a single-atom Pd1/C3N4 catalyst for acetylene hydrogenation. Nano Res. 2017, 10, 1302-1312. [CrossRef]

11. Vorobyeva, E.; Chen, Z.; Mitchell, S.; Leary, R.K.; Midgley, P.; Thomas, J.M.; Hauert, R.; Fako, E.; López, N.; Pérez-Ramírez, J. Tailoring the framework composition of carbon nitride to improve the catalytic efficiency of the stabilised palladium atoms. J. Mater. Chem. A 2017, 5, 16393-16403. [CrossRef]

12. Podyacheva, O.Y.; Bulushev, D.A.; Suboch, A.N.; Svintsitskiy, D.A.; Lisitsyn, A.S.; Modin, E.; Chuvilin, A.; Gerasimov, E.Y.; Sobolev, V.I.; Parmon, V.N. Highly stable single-atom catalyst with ionic Pd active sites supported on N-doped carbon nanotubes for formic acid decomposition. ChemSusChem 2018, 11, 3724-3727. [CrossRef]

13. Podyacheva, O.Y.; Cherepanova, S.V.; Romanenko, A.I.; Kibis, L.S.; Svintsitskiy, D.A.; Boronin, A.I.; Stonkus, O.A.; Suboch, A.N.; Puzynin, A.V.; Ismagilov, Z.R. Nitrogen doped carbon nanotubes and nanofibers: Composition, structure, electrical conductivity and capacity properties. Carbon 2017, 122, 475-483. [CrossRef]

14. Shalagina, A.E.; Ismagilov, Z.R.; Podyacheva, O.Y.; Kvon, R.I.; Ushakov, V.A. Synthesis of nitrogen-containing carbon nanofibers by catalytic decomposition of ethylene/ammonia mixture. Carbon 2007, 45, 1808-1820. [CrossRef]

15. Svintsitskiy, D.A.; Kibis, L.S.; Smirnov, D.A.; Suboch, A.N.; Stonkus, O.A.; Podyacheva, O.Y.; Boronin, A.I.; Ismagilov, Z.R. Spectroscopic study of nitrogen distribution in N-doped carbon nanotubes and nanofibers synthesized by catalytic ethylene-ammonia decomposition. Appl. Surf. Sci. 2018, 435, 1273-1284. [CrossRef]

16. Suboch, A.N.; Cherepanova, S.V.; Kibis, L.S.; Svintsitskiy, D.A.; Stonkus, O.A.; Boronin, A.I.; Chesnokov, V.V.; Romanenko, A.I.; Ismagilov, Z.R.; Podyacheva, O.Y. Observation of the superstructural diffraction peak in the nitrogen doped carbon nanotubes: Simulation of the structure. Fullerenes Nanotub. Carbon Nanostruct. 2016, 24, 520-530. [CrossRef]

17. Evtushok, V.Y.; Suboch, A.N.; Podyacheva, O.Y.; Stonkus, O.A.; Zaikovskii, V.I.; Chesalov, Y.A.; Kibis, L.S.; Kholdeeva, O.A. Highly efficient catalysts based on divanadium-substituted polyoxometalate and N-doped carbon nanotubes for selective oxidation of alkylphenols. ACS Catal. 2018, 8, 1297-1307. [CrossRef]

18. Briggs, D.; Seah, M.P. (Eds.) Practical Surface Analysis by Auger and X-ray Photoelectron Spectroscopy; Wiley: New York, NY, USA, 1983.

19. Jia, L.; Bulushev, D.A.; Podyacheva, O.Y.; Boronin, A.I.; Kibis, L.S.; Gerasimov, E.Y.; Beloshapkin, S.; Seryak, I.A.; Ismagilov, Z.R.; Ross, J.R.H. Pt nanoclusters stabilized by N-doped carbon nanofibers for hydrogen production from formic acid. J. Catal. 2013, 307, 94-102. [CrossRef]

20. Rocha, R.P.; Restivo, J.; Sousa, J.P.S.; Órfão, J.J.M.; Pereira, M.F.R.; Figueiredo, J.L. Nitrogen-doped carbon xerogels as catalysts for advanced oxidation processes. Catal. Today 2015, 241, 73-79. [CrossRef]

21. Luo, J.; Peng, F.; Wang, H.; Yu, H. Enhancing the catalytic activity of carbon nanotubes by nitrogen doping in the selective liquid phase oxidation of benzyl alcohol. Catal. Commun. 2013, 39, 44-49. [CrossRef]

22. Chizari, K.; Deneuve, A.; Ersen, O.; Florea, I.; Liu, Y.; Edouard, D.; Janowska, I.; Begin, D.; Pham-Huu, C. Nitrogen-doped carbon nanotubes as a highly active metal-free catalyst for selective oxidation. ChemSusChem 2012, 5, 102-108. [CrossRef] [PubMed] 
23. Zhou, K.; Li, B.; Zhang, Q.; Huang, J.Q.; Tian, G.L.; Jia, J.C.; Zhao, M.Q.; Luo, G.H.; Su, D.S.; Wei, F. The catalytic pathways of hydrohalogenation over metal-free nitrogen-doped carbon nanotubes. ChemSusChem 2014, 7, 723-728. [CrossRef] [PubMed]

24. Gao, Y.; Hu, G.; Zhong, J.; Shi, Z.; Zhu, Y.; Su, D.S.; Wang, J.; Bao, X.; Ma, D. Nitrogen-doped sp2-hybridized carbon as a superior catalyst for selective oxidation. Angew. Chem. Int. Ed. 2013, 52, 2109-2113. [CrossRef] [PubMed]

25. Zhang, Y.; Zhang, J.; Su, D.S. Substitutional doping of carbon nanotubes with heteroatoms and their chemical applications. ChemSusChem 2014, 7, 1240-1250. [CrossRef] [PubMed]

26. Podyacheva, O.Y.; Ismagilov, Z.R. Nitrogen-doped carbon nanomaterials: To the mechanism of growth, electrical conductivity and application in catalysis. Catal. Today 2015, 249, 12-22. [CrossRef]

27. Kaprielova, K.M.; Yakovina, O.A.; Ovchinnikov, I.I.; Koscheev, S.V.; Lisitsyn, A.S. Preparation of platinum-on-carbon catalysts via hydrolytic deposition: Factors influencing the deposition and catalytic properties. Appl. Catal. A 2012, 449, 203-214. [CrossRef]

28. Kaprielova, K.M.; Ovchinnikov, I.I.; Yakovina, O.A.; Lisitsyn, A.S. Synthesis of Pt/C catalysts through reductive deposition: Ways of tuning catalytic properties. ChemCatChem 2013, 5, 2015-2024. [CrossRef]

29. Vovk, E.I.; Kalinkin, A.V.; Smirnov, M.Y.; Klembovskii, I.O.; Bukhtiyarov, V.I. XPS study of stability and reactivity of oxidized Pt nanoparticles supported on $\mathrm{TiO}_{2}$. J. Phys. Chem. C 2017, 121, 17297-17304. [CrossRef]

30. Podyacheva, O.Y.; Ismagilov, Z.R.; Boronin, A.I.; Kibis, L.S.; Slavinskaya, E.M.; Noskov, A.S.; Shikina, N.V.; Ushakov, V.A.; Ischenko, A.V. Platinum nanoparticles supported on nitrogen-containing carbon nanofibers. Catal. Today 2012, 186, 42-47. [CrossRef]

31. Mason, M.G. Electronic structure of supported small metal clusters. Phys. Rev. B 1983, 27, 748-762. [CrossRef]

32. Wertheim, G.K.; DiCenzo, S.B.; Buchanan, D.N.E.; Bennett, P.A. Core electron binding energy shifts in metal clusters: Tin on amorphous carbon. Solid State Commun. 1985, 53, 377-381. [CrossRef]

33. Ono, L.K.; Yuan, B.; Heinrich, H.; Cuenya, B.R. Formation and thermal stability of platinum oxides on size-selected platinum nanoparticles: Support effects. J. Phys. Chem. C 2010, 114, 22119-22133. [CrossRef]

34. Svintsitskiy, D.A.; Kibis, L.S.; Stadnichenko, A.I.; Koscheev, S.V.; Zaikovskii, V.I.; Boronin, A.I. Highly oxidized platinum nanoparticles prepared through radio-frequency sputtering: Thermal stability and reaction probability towards CO. ChemPhysChem 2015, 16, 3318-3324. [CrossRef] [PubMed]

35. Kim, Y.T.; Ohshima, K.; Higashimine, K.; Uruga, T.; Takata, M.; Suematsu, H.; Mitani, T. Fine size control of platinum on carbon nanotubes: From single atoms to clusters. Angew. Chem. Int. Ed. 2006, 45, 407-411. [CrossRef]

36. Eberhardt, W.; Fayet, P.; Cox, D.; Fu, Z.; Kaldor, A.; Sherwood, R.; Sondericker, D. Core level photoemission from monosize mass selected pt clusters deposited on $\mathrm{SiO}_{2}$ and amorphous carbon. Phys. Scr. 1990, 41, 892-895. [CrossRef]

37. Kawasaki, H.; Yamamoto, H.; Fujimori, H.; Arakawa, R.; Inada, M.; Iwasaki, Y. Surfactant-free solution synthesis of fluorescent platinum subnanoclusters. Chem. Commun. 2010, 46, 3759-3761. [CrossRef]

38. Arrigo, R.; Schuster, M.E.; Abate, S.; Giorgianni, G.; Centi, G.; Perathoner, S.; Wrabetz, S.; Pfeifer, V.; Antonietti, M.; Schlogl, R. Pd Supported on carbon nitride boosts the direct hydrogen peroxide synthesis. ACS Catal. 2016, 6, 6959-6966. [CrossRef]

39. Xia, L.; Li, D.; Long, J.; Huang, F.; Yang, L.; Guo, Y.; Jia, Z.; Xiao, J.; Liu, H. N-Doped graphene confined Pt nanoparticles for efficient semi-hydrogenation of phenylacetylene. Carbon 2019, 145, 47-52. [CrossRef]

40. Bulushev, D.A.; Zacharska, M.; Shlyakhova, E.V.; Chuvilin, A.L.; Guo, Y.; Beloshapkin, S.; Okotrub, A.V.; Bulusheva, L.G. Single isolated Pd2+ cations supported on N-doped carbon as active sites for hydrogen production from formic acid decomposition. ACS Catal. 2016, 6, 681-691. [CrossRef]

41. Shi, W.; Zhang, B.; Lin, Y.; Wang, Q.; Zhang, Q.; Su, D.S. Enhanced chemoselective hydrogenation through tuning the interaction between Pt nanoparticles and carbon supports: Insights from identical location transmission electron microscopy and X-ray photoelectron spectroscopy. ACS Catal. 2016, 6, 7844-7854. [CrossRef]

42. Jang, J.W.; Lee, C.E.; Lyu, S.C.; Lee, T.J.; Lee, C.J. Structural study of nitrogen-doping effects in bamboo-shaped multiwalled carbon nanotubes. Appl. Phys. Lett. 2004, 84, 2877-2879. [CrossRef]

43. Susi, T.; Pichler, T.; Ayala, P. X-Ray photoelectron spectroscopy of graphitic carbon nanomaterials doped with heteroatoms. Beilstein J. Nanotechnol. 2015, 6, 177-192. [CrossRef] [PubMed] 
44. Roldán, L.; Armenise, S.; Marco, Y.; García-Bordejé, E. Control of nitrogen insertion during the growth of nitrogen-containing carbon nanofibers on cordierite monolith walls. Phys. Chem. Chem. Phys. 2012, 14, 3568-3575. [CrossRef] [PubMed]

45. Liu, W.; Chen, Y.; Qi, H.; Zhang, L.; Yan, W.; Liu, X.; Yang, X.; Miao, S.; Wang, W.; Liu, C.; et al. A durable nickel single-atom catalyst for hydrogenation reactions and cellulose valorization under harsh conditions. Angew. Chem. Int. Ed. 2018, 57, 7071-7075. [CrossRef]

46. Vile, G.; Albani, D.; Nachtegaal, M.; Chen, Z.; Dontsova, D.; Antonietti, M.; López, N.; Perez-Ramírez, J. A stable single-site palladium catalyst for hydrogenations. Angew. Chem. Int. Ed. 2015, 54, 11265-11269. [CrossRef]

(C) 2019 by the authors. Licensee MDPI, Basel, Switzerland. This article is an open access article distributed under the terms and conditions of the Creative Commons Attribution (CC BY) license (http://creativecommons.org/licenses/by/4.0/). 